\title{
Does the Month of Birth Influence the Timing of Life Course Decisions? Evidence from a Natural Experiment in Italy
}

\author{
Laura Cavalli \\ Department of Economics, University of Verona, Verona, Italy \\ Email: laura.cavalli@univr.it
}

Received 16 October 2013; revised 17 November 2013; accepted 24 November 2013

Copyright (C) 2014 Laura Cavalli. This is an open access article distributed under the Creative Commons Attribution License, which permits unrestricted use, distribution, and reproduction in any medium, provided the original work is properly cited. In accordance of the Creative Commons Attribution License all Copyrights (C) 2014 are reserved for SCIRP and the owner of the intellectual property Laura Cavalli. All Copyright (C) 2014 are guarded by law and by SCIRP as a guardian.

\section{Abstract}

Social scientists have observed for a long time a negative relationship between the time spent on education and the timing of family formation. Using data from the I.D.E.A. survey (2003), a birth-month experiment on a sample of $\mathbf{3 0 0 0}$ young Italian adults is employed in order to explore whether a different month of birth leads to regular differences in life course decisions of young Italians. The results suggest that the "social" age, as determined by the school cohort, rather than the biological age, is an important determinant of the timing of demographic events during the transition to adulthood.

\section{Keywords}

Education; Marriage; First Birth; Natural Experiment; Kaplan-Meier Estimate; Cox Hazard Model; Logit Regression Model

\section{Introduction}

In the last two decades, fertility choices have had an increasing importance for social and economic dynamics. The emergence of low fertility levels and lowest-low fertility levels ${ }^{1}$ in Europe is also the result of personal decisions taken by individuals during the period known as the transition to parenthood.

\footnotetext{
${ }^{1}$ The fertility level is low when fertility is below replacement, which is below 2.1 children per woman; it is very low when the fertility rate is below 1.5 children per woman; it is lowest-low when fertility is below 1.3 children per woman [3].
} 
Regarding the historic period of demographic change and in particular referring to the trend in the transition to parenthood in low fertility contexts, different issues can be highlighted. First, the postponement of the age at first birth: within the "Second Demographic Transition", Europeans are becoming parents much later than in the past. Actually, the scenario of the Second Demographic Transition is characterized by a control of fertility and the spread of informal union and non-marital childbearing. Second, the traditional order between marriage and parenthood has more often become reversed: in the main European countries, the rise in mean ages at first birth and the increase in extra-marital fertility have continued almost regularly. Third, nowadays extra-marital births are more accepted and widespread even if it persists differences among countries [1,2].

Italy was in the early 1990s one of the first countries to attain and sustain lowest-low fertility levels. In Italy, the mean age of women at childbearing had risen from 27.7 to 30.3 between 1980 and $2004^{2}$ and the mean age at first birth had increased from 25.0 to 28.7 years between 1980 and 1997 and this trend had been shared with many other European and developed countries (Council of Europe). In the most recent years, Italian TFR was having a slightly recover: between 2000 and 2010, it passed from a 1.24 in 2000, to a 1.41 in 2010.

As in [3], in the analyses of the decline of the total fertility rate below 1.3 - or to lowest-low fertility levelsthe authors have argued that the postponement of fertility in connection with the TFR declines is due to two main factors. First, it is due to socio-economic incentives, such as increased returns to education or high level of youth unemployment, which make late childbearing a rational decision for couples or individuals. Second, it is due to social interaction effects, which reinforce the trends towards delayed childbearing through social learning, social influence and other feedback effects that affect the timing of fertility.

Most analyses of the timing of fertility-including those in [3], emphasize the role of human capital investments in early adulthood, and in particular such substantial increases in female's investments in higher or professional education, in response to increased returns to human capital and improved access to the labour market. Referring to Italy, such considered scenario is confirmed: in the last twenty years, the duration of individual's education has been increasingly prolonged and the postponement of life decision could find its roots in this trend.

Prolonged school enrolment reasonably delays the probability of entering a first marriage or a first childbirth, not only for economic reason but also because of the effects of "mos maiorum" which generate an incongruity between the role of being a student and the adult role of being married or being parent. Such transition to adulthood can be schematized as follows: a) completion of education, b) start of first job, c) exit from the family of origin at the time of marriage, d) birth of first child.

From the previous considerations, we infer that many elements influence life decisions. However, there existed unobserved characteristics that play an important role: considering the schooling process and the first birth decision, it is possible to find that exit from education increases the risk of entering the first union, and that individual unobserved characteristics influence the occurrence of the two processes simultaneously. Considering the existence of values that might play an important role in determining the timing of both trajectories, and taking into account the existence of family-oriented people [4] and the presence of some gender differences in the strength of this kind of effects, the present analysis investigates whether a difference in men's and women's month of birth leads to systematic and relevant differences in the age at graduation from school and in the marriage and fertility patterns of Italian people belonging to the cohorts 1966-1971 and 1976-1981. Making use of the "natural experiment" approach, the current study finds that differences in the month of birth have relatively profound effects on the timing of completing education and on the educational attainment and have a slight effect on the timing of marriage, while they do not seem to affect the timing of first birth.

The study is structured as follows: after a brief description of some empirical evidences in Section 2, Section 3 outlines the existing literature and reviews the theoretical and empirical findings of previous studies on the relationship between educational achievement (in particular women's increasing educational attainment) and the timing of marriages and births. After having described the data, Section 4 presents in greater detail the main empirical findings, by considering separately the influences that the month of birth has on a) the schooling leaving age and attainment, b) the decision on the timing of marriage, c) the choice about the timing of first birth. Finally, Section 5 concludes by discussing and summarising the focal findings.

${ }^{2}$ For instance, between 1980 and 1997 the total fertility rate (TFR) in Italy has declined from 1.64 to 1.20; in Spain the mean age at first birth has increased from 25.0 to 29.0 years during 1980 to 1999, while the TFR declined from 2.20 to 1.20 (Council of Europe). 


\section{Some Empirical Evidence}

In order to allow a plain comprehension of the following sections it is essential remind that the different school levels are categorized according to ISCED, the 1997 International Standard Classification of Education, which divides education into seven main categories, ranging from 0 to 6 , that represent schooling from pre-primary to advanced research training levels. In Appendix 1 are presented the six school different levels.

In particular, considering the average number of enrolled people in education across OECD countries, in 2003 half of young adults at some stage during their life entered universities or other institutions offering similar qualifications: on average 32\% completed a first university-level degree. Enrolment in tertiary education, which covers both university-level education and high-level programs, increased between 1995 and 2002 by more than $50 \%$ in the Czech Republic, Greece, Hungary, Iceland, Korea and Poland, and still by more than $20 \%$ in Australia, Finland, Ireland, Mexico, Portugal, Spain, Sweden and the United Kingdom. Austria, France and Germany are the only countries that did not see increases, mainly because rising enrolment rates could not make up for the demographic decline in these countries. Considering the educational attainment of the population 25 - 64 in Italy, measured by average years of education, it has risen from just above 5 years in 1961 to just below 10 years in 2001 (Council of Europe).

Comparing the level of education and the mean age at first birth, it is interesting notice that countries with a higher percentage of population with an advanced level of education experience a first birth in an elder age. Differently in Italy the mean age at first birth is extremely higher but only a small part of the population experiences a higher level of education; in these cases two are the possible explanations: 1) people with a higher level of education are ready to enter early in the adulthood; 2) in Italy exist other factors that influence the age at first birth, not only connected with the level of education attained, but also with social economic reasons.

First marriage is a further important event in early adulthood that is potentially related to an individual's age at graduation. Figure 1 shows the increasing age at first marriage listed in the last years, both for Italy and for European Union Countries: despite Italy reveals a higher mean age at first marriage, the rising trend exists also in the other European Countries.

\section{Education and Family Formation in Developed Countries: A Review of the Literature}

Most accepted theories in the demographic and economic literature [5,6] suggest that female education lowers fertility through an increase in the opportunity cost of women's time where the productive technology for children is time-intensive relative to the parents' technology for their standard of living. In fact, there exist theoretical models that seek to explain the number of children born over the life-cycle highlighting female wages as the key element in the opportunity cost of childbearing. Other models as the ones in $[7,8]$, seek to explain fertility histories as stochastic processes, where the woman is assumed to solve a sequential decision problem under uncertainty. In any case, since returns to schooling are positive, it is induced a negative relationship between education and fertility.

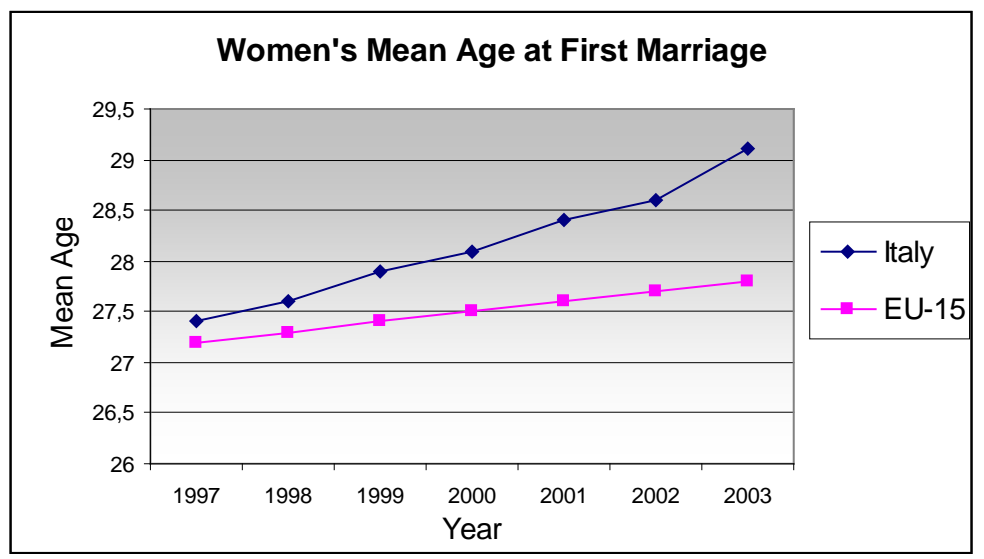

Figure 1. Mean age at first marriage, women. 
Moreover, sociologists pointed out that women usually wait with children until after they have finished their educational careers [9]. This strong effect of enrolment in education on the timing of fertility is caused by several factors [10-12], including the incompatibility of education and childbearing, the increased risk of not completing education due to a birth and the high opportunity costs of failing to complete education, the high lifecycle costs of delaying completing education and delaying the entrance into the labour market, the desire to "establish" oneself in the career after completing education and before having a child, and social norms that discourage childbearing while individuals are still in education. The above incentives and norms have led to a very typical sequencing of demographic events in early adulthood in which the completion of education precedes the first birth [13-15].

Several empirical studies have documented the positive association between education and fertility postponement. The works as in [9,13] and [16] distinguish two roles of education in determining women's fertility decisions: on the one hand, the role of human capital accumulation (i.e., the specific level of qualification acquired) and, on the other hand, the role of educational enrolment itself. Using longitudinal data the authors documented a delaying effect of education on the timing of first marriage and entry into motherhood.

Nicoletti and Tanturri [17] consider the determinants of the motherhood postponement in ten European countries concluding that higher levels of education generally lead to both the postponement of parenthood and the reduction of the probability of the first birth event. According to their findings, an early completion of education and an early entry into the labour market are associated with early entry into motherhood in all European countries.

In short, most dynamic models of fertility behaviour predict the postponement of motherhood as a consequence of enhanced schooling achievement. Husband's education is not expected to exert great effects, even if it plays a role shifting family budget constraint and contributing to the allocation of parents' time between market and non-market activities.

\subsection{Methodological Approaches}

Educational career and family formation represent two important processes shaping the transition from childhood to adulthood, but these features are shaped by the individual's life course strategy: decisions affecting one process are potentially also affecting the other. Thus, in order to understand each process, it is important taking into account their reciprocal relationship and, at the same time, controlling for the possible existence of factors that determine both processes simultaneously.

Despite this emphasis on the role of education and human capital investments and despite the consciousness of a potential causality problem, very few studies have succeeded in establishing the causal effects of "years in education" or "age at graduation" on life decisions. In particular, analyses of this question are hampered by the fact that many unobserved characteristics that affect marriage and fertility are likely to affect also the opportunities or incentives to invest in human capital: standard analyses of the relation between education and fertility are therefore likely to be distorted.

Analyses that can overcome this problem need to rely on instrumental variable techniques, fixed effect models or "natural experiments" [18]. Using an instrumental variables approach, Sander [19] shows that education is endogenous to family decisions such as marriage and divorce, and that educational enrolment should therefore be modelled as an endogenous variable when estimating the risk of getting married. If this endogeneity is ignored, the negative effect of education on marriage is underestimated. Other studies using simultaneous modelling strategies also demonstrate the endogeneity issue.

Boulier and Rosenzweig [20] show that "schooling, marital search and spouse selection are endogenous variables influenced directly or indirectly by the total resources of parents, endowed traits of offspring, the cost of schooling, and marriage market conditions". Finally, Lillard and colleagues [21] argue that education and family formation behaviours are related not only through direct cross effects, but also because the allocation of time between schooling and family formation is driven by individual preferences for both kinds of activities, and for their future consequences. Therefore, the same unobserved individual characteristics influence both marriage and education processes but in opposite directions. This shows that a higher propensity toward family formation results in lower investments in human capital, and vice-versa.

Given that the instrumental variables technique assumes that some components of non-experimental data are random and since this near perfect random treatment has been subject to scepticism, in recent years economists, 
in recognition that nature itself provides perfect randomness with respect to important variables, have exploited naturally random events as instrumental variables $[22]^{3}$.

\subsection{Birth-Month as a Natural Experiment}

Several studies have documented the effects of the birth month on phenomena such as the risk of suffering from schizophrenia [23] and on life expectancy [24] The use of the birth month in econometric studies of causal influences in behavioural relations, however, is quite new. Angrist and Krueger [25] pioneered this approach in the investigation of the relationship between earnings, educational attainment, and school regulation in the United States, where school regulation stipulates a minimum age at graduation that differs over time and across American States. In such a context children born in the first four months of the year will have received less education if they drop out of school when they turn 16, so in the adulthood they will receive a lower wage.

The study by Angrist and Krueger stimulated several follow-up investigations: Bound and Jaeger [26] provide evidence from cohorts predating the compulsory schooling laws that the link between season of birth and educational and labour market success can be at least partially explained by factors other than schooling laws.

The Swedish school enrolment rules make Sweden a suitable subject for using birth-month-induced variation in the timing of education and age of graduation as a natural experiment. In fact Swedish students are subject lo laws on the age of school entry and graduation. A normal Swedish school year starts at the end of August and lasts until the beginning of June the next year. Primary school starts for almost all children the year they turn 7, lasts for nine years and is finished in June, the calendar year the pupils turn 16. Graduation at younger ages is impossible, and graduation at older ages is rare. The school entry cut-off-date mechanism means that those born in January enter school 11 months later than those born in the previous December.

In their investigation, Skirbekk, Kohler and Prskawetz [27] use the exogenous variation in school graduation resulting from differences in birth month to estimate the effect of duration of education or age at graduation on the timing of births and marriage in Sweden. In their analysis they move toward age at first birth, age at first marriage and school-leaving age. Using data based on the Swedish registration system that provides comprehensive information on fertility and other life course events as well as socio-economic background variables for almost all Swedish women born 1946-62 (in particular 891,066 Swedish women) they observe a postponement both in the age at first marriage and in the age at first birth: in Sweden first birth increases from 23.8 years to 26.3 years, and this overall trend is consistent with the diffused postponement of childbearing. For those being married, the timing of marriage changes in close agreement with the timing of fertility: the average age at first marriage increases from 24.6 years to 27 years across the cohorts born 1942-62. Moreover they find that the difference of 11 months in the age at school-leaving between women born in two consecutive months, December and January the following year, implies a delay in the age at first birth of 4.9 months. Considering the school-leaving age they find that the risk of completing tertiary education is lower for those born from July to December, while the birth season's effect on completing a 3-year secondary education is much weaker. This point is extremely important referring to consequential performance, because it reflects what Thompson, Barnsley, Stebelsky [28], Alton and Massey [29] and Plug [30] call relative class-age effect: those who enter school at a later age behave like their school friends, but perform better as they are older in their social reference group (the school class). Breznitz and Teltsch [31], find that first graders who are older in class are more socially successful and do better in subject tests than their classmates, and a previous study by Alton and Massey [29] suggests that these relative class age effects remain throughout the school years [32]. Moreover, Grendler [33] shows that postponing the age of school entry does not seem to improve student performance, which demonstrates that is not age per se that is the main cause of within-class performance differences. In summary, women who are born in the first months of the year have a slightly higher risk of completing a tertiary education relatively to those born later in the year. The higher educational attainment of those born early in the year corresponds with the relative-class-age hypothesis.

\section{Empirical Analysis of I.D.E.A. Data}

Using individuals belonging to two different cohorts, precisely 1966-1971 and 1976-1981, the central focus of

${ }^{3}$ Five major random outcomes have been used as instruments: twin birth, human cloning (monozygotic twins), birth date, and gender and weather events [18]. 
the present investigation explores whether a different month of birth leads to regular and relevant differences in the life decisions of Italian people. In order to settle this question, it is employed the natural experiment approach and it is applied the same strategy followed in [27]: the assumption that parents cannot time the births of their children very accurately to the exact month is an universal rule and it is, of course, shared by both the Italian and the Sweden case.

\subsection{Hypotheses}

In the present work the effect of the month of birth on several outcomes that relate to "positive" events in adult life as it was made with a sample of Swedish women in 2003 are investigated. These variables include educational attainment, marriage and the first birth.

The low cohabitation experience performed by the Italians with respect to the higher tendency experienced by the Swedish induces to think about a profoundly different socio economic background between the two countries: Italy is a country traditionally based on marriage and characterized by the conventional image of family and even if in the third millennium marriage is no longer central in the family formation process it is still steady in the Italian scenario. Long-term, stable cultural factors also contribute to reinforcing differences; moreover, considering the institutional settings and the main features of the welfare state there exist differences that can explain significant divergences in behaviours. For all these reasons from the following analysis is expected to find a stricter connection and a one-way direction among the three "positive" events experienced by the Italians, with evidence of the still existing rigid sequencing of events.

\subsection{Data and Methods}

The data used are drawn from the I.D.E.A. (“Inizio Dell’ EtàAdulta”-Beginning of Adulthood) cross-sectional survey, carried out between December 2003 and January 2004 on a national-representative sample of more than 3000 young Italian individuals belonging to cohorts 1966-1971 and 1976-1981. The survey collects data on life course transitions, especially focusing on the relationship existing between respondents and their parents, and respondents and their partner. Making use of data obtained from the research I.D.E.A two cohorts are considered, specifically 1966-1971 and 1976. This decision allows taking account of a few observations that fall out of the former cohorts: basic summary statistics for these variables are reported in Appendix 2.

Considering that the data refer to young individuals, ages (at educational attainment, at first marriage and at first birth) are treated as survivor time to exit from the previous status and Kaplan-Meier Survivor Function are computed. Individuals may either enter the adulthood event during the considered period or be right censored at the time of the survey; people who have not finish studying, or who are not married, or who are not parent at the time of the survey constitute censored cases and just the age they declare during the interview is report.

As for the more detailed part of the study the hazard regression Cox model is used, which allows to properly estimating the survivor functions. In order to understand if the month of birth influences the risk of experience a specific event, logit regression estimates are employed.

\subsection{The Month of Birth and Its Effect on the Duration and on Timing of Education}

Variation in the school leaving age can affect the timing of demographic and labour market events. Leaving school tends to precede entry to the labour market and parenthood, and increases in the graduation age have been associated with increases in the age of marriage market entry, age of childbearing, and the timing of other events in adulthood [34].

In the actual analysis, cohort 2 refers to the individuals who belong to the cohort 1966-1971 and cohort 3 refers to the younger one. The main divergence between the two cohorts exists considering the period committed to an upper secondary education: youngest individuals decide to invest more time and to devote a higher number of years in order to reach an advanced level of education.

This consideration is also confirmed by the percentage of youngest respondent (83.86\%) who is less likely to have lower secondary schooling as its highest educational attainment with respect to the respondents belonging to the older cohort $(71.16 \%)$.

Considering separately males and females there are not significant differences but the most relevant thing to note is the high mean age in which individuals leave education (21.7 year): it is important evaluate if it coincides 
with a high level of educational attainment or with a protracted time employed for reaching the desired educational level. ${ }^{4}$.

In Table 1, making use of the logistic regression the probability of attaining at least specific levels of education after having attained the primary school is analysed: the month of birth for those born later in the year plays an important role. It look as if those born in October, November or December are less likely to have primary schooling as their highest educational attainment and more likely to have achieved more advanced education. This result is not always valid and robust: if it is considered the highest level of education, the month of birth does not have any significant influence. Taking into consideration the tertiary education, in correspondence of the last part of the year is possible to observe that the coefficients change their sign; in this case it seems that those born in the first months of a year are the most "profitable" in terms of higher educational attainment.

In order to treat separately the two cohorts, the sample have been disentangled and the logistic regression is run individually after having checked that there exists a cohort effect: from the analysis, the youngest cohort does not reveal any significant coefficient ${ }^{5}$ that can explain if the month of birth has or not a positive influence on the risk of attain specific levels of education.

On the contrary, the cohort 1966-1971 reveals that those born in the first months of a year are the "less successful" in terms of educational attainment, but the month of birth does not have any influence on tertiary or advanced education and again the tertiary education presents a changing sign of the coefficient in correspondence of the last months of the year.

The positive and significant coefficients for what concern those born in October and December means that it is easier to observe at least the secondary (lower and upper) education in youngest individuals than in oldest ones (computing the age differentials in months).

An important issue to take into account is the young age of the individuals who belong to the cohort 1976-1981. Some respondents have probably not yet completed the Tertiary education and certainly very few have reached the highest educational level: that consideration could help in explaining the lack of significance of the whole coefficients for the Tertiary and the advanced education.

Although the young age of the cohort 1966-1971, an important issue deserves attention: after having completed the compulsory schooling, the majority of the youngest respondents keeps on studying attending the Secondary school.

\begin{tabular}{ccccc}
\hline \multicolumn{5}{c}{ Table 1. Risk of attaining specific levels of education. } \\
\hline \multicolumn{5}{c}{ Risk of attaining specific levels of education } \\
\hline Birth Month & Lower Secondary & Upper Secondary & Tertiary & Advanced \\
\hline January & Ref. Cat. & Ref. Cat. & Ref. Cat. & Ref. Cat ${ }^{\S}$. \\
\hline February & -0.39 & 0.34 & -0.13 & 0.05 \\
March & 0.27 & 0.31 & 0.05 & 0.12 \\
April & 0.34 & 0.37 & 0.00 & 0.02 \\
May & $0.47^{* * *}$ & 0.33 & $0.31^{*}$ & 0.30 \\
June & $0.43^{* * *}$ & $0.44^{* *}$ & 0.11 & 0.17 \\
July & 0.12 & 0.24 & -0.15 & 0.01 \\
August & 0.18 & 0.04 & -0.14 & 0.03 \\
September & 0.08 & 0.053 & -0.31 & -0.36 \\
October & $0.69^{* * *}$ & $0.45^{* * *}$ & -0.14 & 0.07 \\
November & $0.19^{*}$ & $0.10^{*}$ & -0.18 & -0.01 \\
December & $0.32^{*}$ & $0.16^{*}$ & -0.14 & -0.23 \\
\hline$* * * *$
\end{tabular}

\footnotetext{
${ }^{4}$ In order to check if this old age means a higher level of education attained the number of years employed studying for every respondent has been controlled, taking into consideration the Italian classification of education and not considering the failures.

${ }^{5}$ The only exception is August: those born during this month seem more likely to achieve more advanced education.
} 
Table 2 reports the results treating separately males and females: it shows that for females the impact of the birth of months on the risk of attaining specific levels of education is weaker than for males. Even if the previous argument remains valid, so that being born during the last quarter of the year means a higher probability of having reached a highly developed level of education, this influence is heavier for men.

Above all, it is possible note that for males, not only been born in winter, but also been born in spring has a significant influence on the level of education attained; also in this case, the month of birth does not hold sway over Tertiary and advanced education.

The basic assumption of the analyses is that parents cannot fine-tune the birth of their children at the level of the birth month, and that the month of birth of a person is exogenously determined.

Moreover, the month of birth does not affect school exit age through any other mechanism than the age at school entry as determined by the school enrolment. Because of the not so rigid Italian school system up to the completion of primary school, this assumption could not result always very plausible. For Secondary and Tertiary schooling, however, individuals (or their parents) make conscious decisions about continuing the educational

\section{Table 2. Risk of attaining specific levels of education, both cohorts, by gender.}

\begin{tabular}{|c|c|c|c|c|}
\hline \multicolumn{5}{|c|}{ Risk of attaining specific levels of education } \\
\hline Birth Month & $\begin{array}{c}\text { Lower Secondary } \\
\text { School (at least } 3 \text { years) }\end{array}$ & $\begin{array}{l}\text { Upper Secondary } \\
\text { Education (5 years) }\end{array}$ & $\begin{array}{l}\text { Tertiary Education } \\
\text { (at least } 3 \text { years) }\end{array}$ & $\begin{array}{l}\text { Advanced } \\
\text { Education }\end{array}$ \\
\hline January & Ref. Cat. & Ref. Cat. & Ref. Cat. & Ref. Cat ${ }^{\S}$. \\
\hline \multirow{2}{*}{ February } & 0.13 & 0.21 & -0.06 & 0.08 \\
\hline & 0.63 & 0.50 & 0.17 & 0.05 \\
\hline \multirow{2}{*}{ March } & 0.23 & 0.23 & 0.13 & 0.15 \\
\hline & 0.31 & 0.38 & 0.05 & 0.07 \\
\hline \multirow{2}{*}{ April } & -0.01 & 0.10 & -0.22 & -0.17 \\
\hline & $0.67^{* *}$ & 0.63 & 0.25 & 0.23 \\
\hline \multirow{2}{*}{ May } & 0.27 & -0.01 & $0.40^{*}$ & 0.18 \\
\hline & $0.65^{* *}$ & $0.65^{*}$ & 0.22 & 0.45 \\
\hline \multirow{2}{*}{ June } & 0.12 & 0.05 & 0.05 & -0.09 \\
\hline & $0.74^{* *}$ & $0.82^{*}$ & 0.18 & 0.44 \\
\hline \multirow{2}{*}{ July } & -0.14 & -0.15 & -0.14 & 0.07 \\
\hline & 0.38 & 0.61 & -0.12 & -0.01 \\
\hline \multirow{2}{*}{ August } & -0.08 & $-0-39$ & -0.14 & 0.23 \\
\hline & 0.43 & $0.47^{*}$ & -0.14 & -0.25 \\
\hline \multirow{2}{*}{ September } & 0.05 & -0.21 & -0.31 & -0.21 \\
\hline & 0.16 & 0.32 & -0.30 & -0.51 \\
\hline \multirow{2}{*}{ October } & 0.27 & 0.03 & 0.20 & -0.18 \\
\hline & $0.13^{* * *}$ & $0.86^{* * *}$ & -0.06 & 0.34 \\
\hline \multirow{2}{*}{ November } & -0.29 & -0.26 & -0.20 & -0.06 \\
\hline & $0.72^{* *}$ & $0.46^{*}$ & -0.16 & 0.07 \\
\hline \multirow{2}{*}{ December } & $0.71^{* *}$ & $0.18^{*}$ & 0.09 & -0.11 \\
\hline & $0.16^{*}$ & $0.19^{*}$ & -0.40 & -0.37 \\
\hline
\end{tabular}

${ }^{* * *}=$ Significant at $\mathrm{p}<0.01$ Level, ${ }^{* *}=$ Significant at $\mathrm{p}<0.5$ Level, ${ }^{*}=$ Significant at $\mathrm{p}<0.1$ Level, ${ }^{\S}$ Reference Category. 
process. These decisions can potentially include the consideration of birth month and its implications for the age at graduation, the age at first marriage and the timing of other demographic events.

\subsection{The Month of Birth and Its Effect on the Age at First Marriage}

Thanks to the analysis of the mean age at first marriage for the sample under investigation it is possible to highlight the increasing age at which women decide to get married in particular for women born between 1966 and 1969, by confirming both the previous considerations about the widespread trend in the postponement of adulthood decisions and the strong relation with the increasing duration of the educational process.

In order to conduct the analysis in a correct way, the first marriage and the first birth are treated focusing only on women born between 1966 and 1971: the youngest cohort is too young to give significant results, even if I try to predict the behaviour of the youngest women by using the Kaplan Meier Survivor Function.

Considering the fact that those born in the last part of the year are more inclined to study for a longer time, it could be expected that women born in the first part of the year anticipate the age at first marriage. I try to inspect if the month of birth is an important determinant for the decision of getting married running an Ordinary Least Square regression on the sample of oldest women who have yet experienced the event, precisely on a sample of 587 women (on a total of 746). The month of birth does not result to be a significant explicative variable among the married women born during the first part of the year, even if be born in the last two months of a year seems to exert an influence on the event: looking at the sign of the coefficients, be born in November or in December appears to affect negatively the first marriage decision. On the contrary the sign of the coefficient for individuals born in February is negative and this suggests that those born in the last two months of the year get married later. Although this is in line with the consideration about the influences of the longer duration of education on adulthood decisions, the coefficients are not significant.

After having conducted such analysis the Kaplan Meier Survivor Function is run in order to consider also the censored cases and the part of women who have not already experience the event.

Figure 2 plots the Kaplan Meier Survivor Function for all the oldest women in the sample, both married and not and it tries to check if there exist significant differences in the timing of first marriage between women born in January and those born in December. It seems that women born in December tend to delay the first marriage of 2.5 months (in mean) with respect to the women born in the first month of the year. Within a birth cohort, women who are born early tend to marry at a younger age than women who are born later in a calendar year. To support further the finding that women born in the last part of the year get married later ${ }^{6}$ it could be interesting also estimate an event history model by comparing the two cohorts and checking if women born from January to

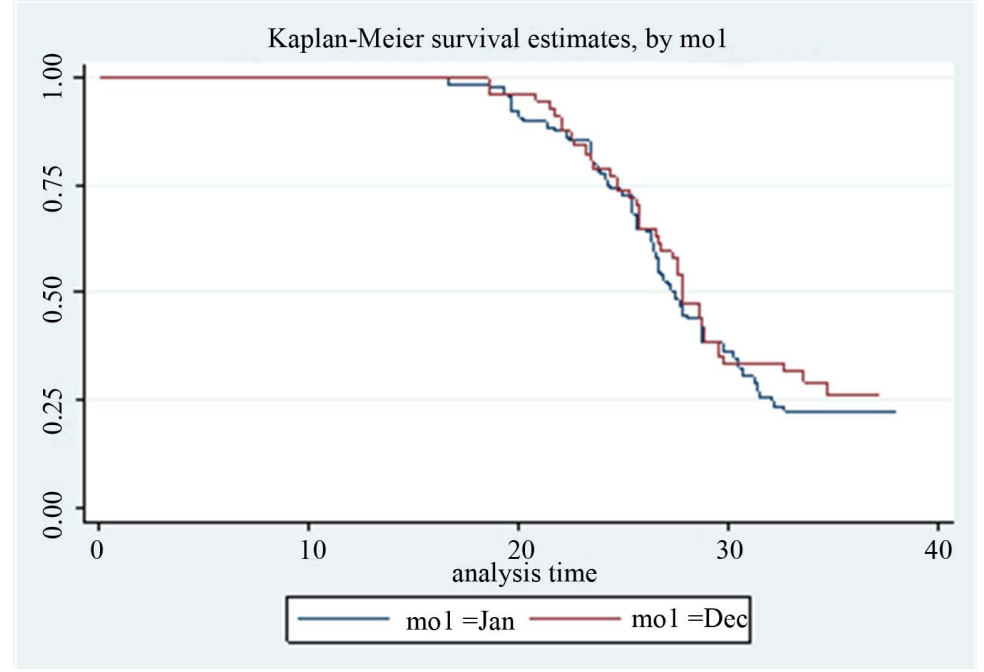

Figure 2. Kaplan-Meier survival estimates, women born in December and in January (COHORT 1966-1971).

\footnotetext{
${ }^{6}$ This happens because they study more time than the women born in the first quarter of the year.
} 
June have a lower or a higher risk of marrying up to a fixed age. However this consideration, the sample under analysis provides a cohort of really young individuals: the majority of the respondent who belongs to the cohort 1976-1981 is still at risk of experiment the event "first marriage", so it is not possible control immediately such relation.

The whole sample has a higher probability of experiment the event "first marriage" between 24 and 29 years old and that trend is as expected carried away by the oldest cohort. Actually the comparison between cohort shows the really young age that women belonging to the cohort 1976-1981 have: giving a cursory glance at the graph seems that the younger women get married until reach the 24 years. Finally it is worth noting that in this case the survivor function for the youngest people is flatter than the one for the oldest cohort.

At this point the analysis employs a Cox Regression Model and it calculates if be born in the first part of a year really affects choices of autonomy. As expected, women born in the last part of a year present a negative coefficient with respect to the others that are born in the first part of the year, even if the coefficient are not always significant: the relative youngest women have a lower probability of getting married with respect to the younger contemporaries. That result strengthens the hypothesis that individual's decisions are interconnected one to each other and that the sequencing of the events in adulthood is still present. Although school attainment and birth month mostly affect the timing of marriage, the overall probability of marriage deserves specific attention. In particular Table 3 reports the results of a logit regression of the probability of having been married by age 27.4: women born late in a year have a lower probability of marriage than women born early in the year, that is, it seems to be a higher risk of experiment the event for women born in the first part of the year than for the other ones ${ }^{7}$.

In order to verify if the influence of the month of birth on the decision of getting married persists after having controlled for the educational attainment a Cox regression model is run. In the right panel of Table 3 the results of the estimate are reported. Looking at the sign of the coefficients, it is interesting notice that women born in the last part of the year present a negative coefficient with respect to the others that are born in the first quarter

Table 3. Women risk of first marriage (COHORT 1966-1971).

\begin{tabular}{|c|c|c|c|}
\hline \multicolumn{2}{|c|}{ Marriage risk (until age 27.4) } & \multicolumn{2}{|c|}{ Marriage risk } \\
\hline \multicolumn{2}{|c|}{ Logit regression results } & \multicolumn{2}{|c|}{ Proportional hazard Cox model } \\
\hline Birth Month & & Birth Month & \\
\hline January & Ref. Cat. & January & Ref. Cat ${ }^{\S}$ \\
\hline February & 0.39 & February & 0.04 \\
\hline March & $0.44^{*}$ & March & 0.26 \\
\hline April & $0.27^{*}$ & April & -0.11 \\
\hline May & $0.68^{* *}$ & May & 0.04 \\
\hline June & 0.53 & June & -0.38 \\
\hline July & 0.42 & July & 0.14 \\
\hline August & 0.38 & August & 0.04 \\
\hline September & 0.49 & September & -0.10 \\
\hline October & 0.21 & October & -0.09 \\
\hline November & 0.21 & November & -0.17 \\
\hline December & -0.07 & December & -0.16 \\
\hline & & Edu. Attainment & $-0.078^{* * *}$ \\
\hline
\end{tabular}

${ }^{7}$ The logit regression is run on the sample of the 746 older women: women who belong to the cohort 1976-1981 are too young to be considered suited for the current aim. 
of the year. These further signals are coherent with the previous considerations and, moreover, contribute to reinforce the existence of the theory of the sequencing of the events.

\subsection{The Month of Birth and Its Effect on the Age at First Birth}

Even the Italian school enrolment system is not rigid as the Swedish one, before 2004 the schooling legislation did not allow to enrol children before they turn six ${ }^{8}$. This element implies that all women born in the same calendar year enter primary school in the same year-the year they become six years old- and variations in birth month is supposed to translate directly into differences in the age at completing Primary and potentially also Secondary and Tertiary education: within a birth cohort, women born in January are the oldest at graduation, exceeding the age of December-born women in the same birth cohort by eleven months, and across two birth cohorts, women born in December in the first cohort are eleven months younger at graduation than women born in January in the subsequent birth cohort.

Because the data are based on register data with a large number of young women simply the mean age at first birth by year of birth for women belonging to the cohort 1966-1971 are plotted because the majority of the youngest women have not yet experienced the event "first birth". The mean age at first birth for the sample under analysis reflects what is recorded in Italy and in the majority of the European Countries: in the course of the years, individuals decide to postpone the event "first birth". In particular between women born in 1966 and those born in 1969 there exists a clear evidence of belated childbearing. Again, women born after 1970 seem to anticipate the (mean) age at first birth with respect to the trend delineated by the other women, but we are not in presence of a sharply change of tendency ${ }^{9}$. It is also important bear in mind that the exiguous number of respondents born in 1971 (and their relative younger age at first birth) could once more drag to an underestimate of the results ${ }^{10}$.

If there exist a rigid sequencing, so that Italian women decide first the duration of education, than the age at which leaving home and get married and only after a marriage the age at which experience a first birth, it is coherent expected that the age at first birth follows the performances of the other adulthood decisions. Precisely it is plausible thinking that 1) women belonging to the 1976-1981 cohort experience later a first birth with respect to the sample of women born ten years before; 2) women born at the end of the year become mothers later than women born in the first months of the year as they postponed the end of education and the first marriage.

The first consideration is quite tricky to control with the sample of data in use; actually the higher age at which women belonging to 1976-1981 cohort become mothers is only a reasonable hypothesis starting from the assumption that the $79 \%$ of the sample has not yet experienced the event "first birth"11.

Moreover the other 21\% has had a first birth at a real young age (in mean 21 years) and this will outcome in an altered result. Specifically the mean age at first birth provided by the Kaplan Meier Survivor Function Estimates using the available data on all the sample of women would supply an altered result and it could be in large partly due to the women young age (referring to the cohort 1976-1981). All the reasoning is confirmed by looking at Figure 3: women belonging to the cohort 1976-1981 seem to anticipate the first birth event, but again the result appears deceitful.

With the intent to verify if the decision about the timing of first birth is in line with the decision about first marriage and education, a Kaplan Meier Survivor Function for all the oldest women in the sample is run. Differently from the analysis on the first marriage I decide not to run an OLS estimate on the sample of women who have already experienced the event under investigation: in a chronological sense the first birth is experienced later than marriage and the brief interval between the interview and the event could lead to feeble results.

In order to consider also the censored cases, Kaplan Meier Survivor Function are run both for women who

\footnotetext{
${ }_{8}^{8}$ In spite of that law, parents might decide to enrol their children in private school where was accepted the illegal but commonly widespread "primina" phenomenon. With the 2004 law by degree a change is provided for this case: children that are reckoned precocious could be legally enrolled at the age of 5 if they turn six till the 30th of April.

${ }^{9}$ As stated before for the mean age at first marriage presented in Figure 4.2, the more recent an event is experienced, the more difficult is to carry out a precise estimate: for that reason figure 4.5 shows a deeply decrease in the mean age at first birth for individuals born in 1970 and 1971 that could be the result of an underestimate of the variable under examination.

${ }^{10}$ On a total of 766 women belonging to the cohort 1966-1971, 548 have experience the event first birth. Among those women, only 12 (the 2.18\%) are born in 1971.

${ }^{11}$ The Kaplan Meier Survivor Function for all the women in the sample provides a 26.24 median age at first birth which results to be really under the level of the median age at first birth experienced by the oldest women (29.96): if the result was absolutely accepted it will be in clear opposition with the previous comment.
} 
have already had a child and for women who have not already experienced the event. On average, women born in December of one year experience the first birth later than women born at the beginning of the year. From a theoretical perspective, the above finding is important because many economic or rational choice theories about the timing of fertility suggest that women have specific preferences about what their ages at first birth should be. After having employed a proportional hazard Cox model and after having looked at the magnitude of the coefficients it is possible grasp that women born in the first half of a calendar year tend to have higher first-births hazards as compared to women born in the second half of the year. Again those born in the last quarter of the year have a moderately lower risk of first birth especially with respect to the women born between January and April. In brief, the observation that women born early in a calendar year "act younger" and that those born late in a year "act older" is still almost valid and consistent with previous considerations.

Although it is not possible provide evidence of the birth-month effect on the overall probability of experience a first birth, it is likely to investigate the probability of having had a first child by an exactly age, namely the mean age at first birth registered in Italy in 1997; the reference year is the same used for conducting the analysis for the mean age at first marriage, that is the first year in which Italy registered an increase in the mean age at first marriage (this consideration is in line with the assumption of a disseminated continued existence of a rigid sequencing). Specifically Table 4 (left panel) reports the coefficients of a logit regression of the probability of having experienced a first birth by age 28.7. As in the previous investigations, the right-hand-side variables of these logistic regressions include dummy variables for birth month. Again January is used as reference category: the number of women who has experienced the event first birth or who is still at risk shows a regular distribution with respect to the month of birth, thus the number of observations by month of birth does not impair the results. The coefficients for women born in February, March and May result significant: the risk of having a first birth within 28 years results to be crucial for relatively older women.

The obtained results are in line with earlier interpretations regarding the interconnection between the events graduation, first marriage and first birth: women born late in a year still have a lower probability of experience a first birth within 28.7 years than women born early in the year, that is, it seems to be a higher risk of come across a first pregnancy for less educated women (consequently for those who get married early) so for those born in the first part of the year than for the other ones. In a more general outlook it appears that the lower level of education induced by the fact of been born at the beginning of a year, lowers the risk of getting married; then it is reasonable thinking that a delay in marriage has effects on the timing of having children since it directly affects completed fertility by reducing the number of years available for childbearing. In order to strengthen the latter considerations and to provide evidence of the influence of the month of birth on the risk of experience a first birth, a Cox Regression controlling for the educational attainment of the sample of women under analysis is run. Like Table 3 (right panel), the right panel of Table 4 reports a slight evidence of the influence of the month of birth on the risk of first birth. Women born in the last months of a year present a coefficient with a negative sign so I can conclude that they tend to experience a first birth later than their relative older contemporaries that present positive coefficients.
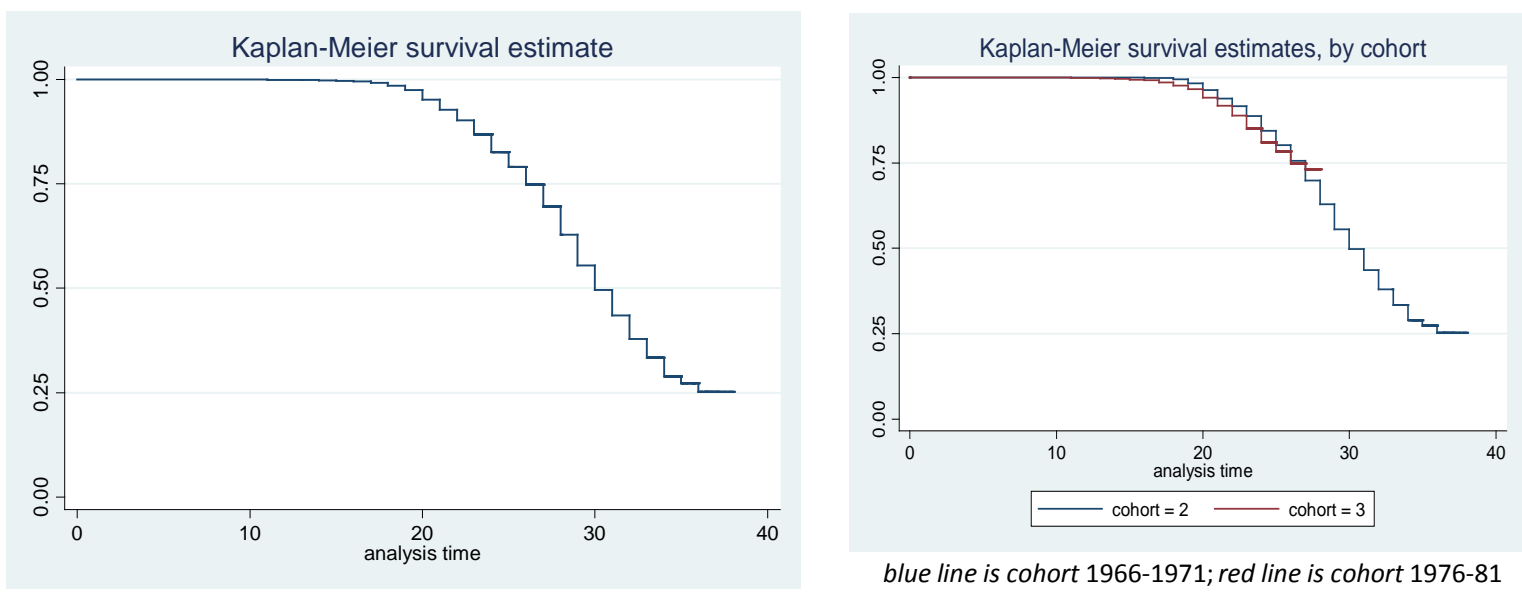

Figure 3. Kaplan-Meier survival estimates, all women. 
Table 4. Women risk of first birth (COHORT 1966-1971).

\begin{tabular}{cccc}
\hline Risk of first birth (until age 28.7) & \multicolumn{2}{c}{ Risk of first birth } \\
\hline \multicolumn{2}{|c}{ Logit regression results } & Proportional hazard Cox model \\
\hline Birth Month & \multicolumn{3}{c}{ Birth Month } \\
\hline January & Ref. Cat. & January & Ref. Cat ${ }^{\S}$. \\
February & $0.84^{* *}$ & February & 0.04 \\
March & $0.75^{*}$ & March & 0.23 \\
April & 0.29 & April & -0.88 \\
May & $0.98^{* *}$ & May & 0.02 \\
June & 0.48 & June & -0.35 \\
July & 0.63 & July & -0.03 \\
August & 0.31 & August & -0.10 \\
September & 0.18 & September & -0.35 \\
October & 0.34 & October & -0.07 \\
November & 0.37 & November & -0.09 \\
December & 0.18 & December & -0.18 \\
& & Edu. Attainment & $-0.08^{* * *}$ \\
\hline *** $=$ Significant at $\mathrm{p}<0.01$ Level, ${ }^{* *}=$ Significant at $\mathrm{p}<0.5$ Level, ${ }^{*}=$ \\
Significant at $<0.1$ Level, ${ }^{\S}$ Reference Category.
\end{tabular}

\section{Discussion}

Age constitutes one of the most central variables in demographic theory and research. In recent years, many theoretical and empirical studies have focused on explaining the changes in the timing of demographic events during early adulthood, and in particular, on the postponement of fertility and marriage.

The availability of the new and recent data gathered with the I.D.E.A. survey has offered a unique possibility to analyse the timing and path of transition from youth to adulthood of young Italians; in particular, I have observed behaviours of cohorts born between 1966-1971 and 1976-1981.

In this work, with the use of a "Natural Experiment" approach, I find that Italians belonging to the cohort 1966-1971 and 1976-1981 and born in the last months of a year are more inclined to reach higher level of education, that is, they study for a prolonged time. In other words, the relatively older individuals, i.e., Italians born in the first quarter of a year are subject to substantial losses in terms of human capital levels.

Referring to the life decisions course and considering the validity of the theory of sequencing nowadays largely eradicated in the Italian culture, women who study more seem to experience a later first marriage and a later first birth with respect to those who exit early from the educational process namely women born in the first months of a year. On the other side, it is necessary to highlight that women born in November or December are "by definition" younger with respect to women born in January of the same year. As a matter of fact, they enter into adulthood some months in advance and experience life events early with respect to their relative older contemporaries. This evidence has an opposite effect on the postponement of life events: ceteris paribus an individual born in December, experiences the life events with an eleven months' difference (eleven month early) with regard to the individual born in January of the same year.

The two quoted features work into two different directions, producing a balanced effect: the former emphasizes the postponement of life events for respondents born in November or December; the latter reflects the natural age differences within individuals born in the same year. Thus, the month of birth does not produce a oneway effect on the timing of life course decisions for the young Italian individuals under analysis and in particular for the Italian women, but its consequences on marriage and on first birth are counter-balancing. To sum up, schooling policies that aim to lower the school-leaving age while increasing educational quality, could play a role in terms of rejuvenating the labour force, speeding up the fertility dynamics and increasing the sustainability 
of the public pension system only if they are introduced where there exist the suitable conditions for the development of their effects.

Our findings are profoundly different from those of Skirbekk, Kohler and Prskawetz [27]. A striking finding of their analyses is that differences in the age at graduation from primary school for Swedish women belonging to the 1946-1962 cohort have substantial and long-lasting effects. For instance, $45 \%$ of the eleven-month age difference in graduation between women born in December and the subsequent January is still present in the age at first birth. This result means that in Sweden the two previous considered effects move in the same direction: women who are born in the last months of a year are less likely to reach higher level of education and more likely to enter early into adulthood. The relative (and natural) younger age, precisely the fact that Swedish born in November or December have 10 - 11 months less than their contemporaries, strengthens the final outcome: women born in January are on average 2.1 months older when they marry for the first time than women born in December the same year, and there is a difference of 11 months in the age at school-leaving between women born in two consecutive months, December and January the following year; and it implies a delay in the age at first birth of 4.9 months. In Sweden, the assumption suggests that a change in the school-leaving age would be likely to affect fertility patterns and that a younger school-leaving age would be likely to lead to a younger age at childbearing.

The deep divergence in the two considered countries could be due to the different available sources of data employed in the analysis, and/or to important differences in the social structure and in the two legislations, and differences that are also in line with the recent debates (European Population Conference, 2005). These all lead to the conclusion that a convergence in patterns of union formations and first births may not occur in Europe, consequently that Europe is likely to be characterized by distinct national and regional patterns in the near and intermediate future.

Firstly, in Sweden, the school legislation is rigid and that makes Sweden a suitable subject for using a birthmonth natural experiment: children are enrolled in school in the calendar year in which they become seven years old. So children who are born during two consecutive months, December and January, therefore graduate in two different calendar years. Hence, they differ by almost one year in the age at graduation from compulsory schooling, despite the fact that they are born merely one month apart on average. Differences in age at finishing primary education therefore have an immediate repercussion on the timing of demographic events that follow several years after finishing primary education. On the contrary, in Italy, such a rigid schooling legislation does not exist: if the child is enrolled in the previous calendar year he/she becomes six, he/she has the opportunity to reach the same higher educational level with some months in advance compared to the children born in the last three quarter of the same year. This important difference could affect our findings and results.

Secondly, the strong connection is absent in Sweden among leaving the parental home, entering marriage and childbearing, largely disseminated in Italy: such element might allow catching the influence of the month of birth on the life decisions better in Sweden than in Italy.

Furthermore, the two analyses differ in terms of level of significance of the obtained results and the reason could be find in the different availability of data. In particular, their dataset is based on the Swedish registration system and provides comprehensive information on fertility and other life course events as well as socio-economic background variables for almost all Swedish women born 1946-62. Particularly, their data consist of 863,304 Swedish women born in Sweden during 1946-62. The data include information on dates of various demographic events (child birth, marriage, divorce, death, emigration and immigration) and longitudinal observations on important economic variables such as income or public study benefits that occur prior to December 31, 1999. Differently our employed dataset consists of 1558 Italian women born between 1966 and 1981, and the majority of them have not yet completed the transition to adulthood. This reflects the importance of making longitudinal administrative data available also in Italy to investigate life-course behaviours.

Another element of specific interest is the level of significance of the actual findings. Precisely, the fact that I used new and recent data gathered with the I.D.E.A. survey if on one side it has offered me a unique possibility to analyse the timing and paths of transition from youth to adulthood of young Italians, on the other hand it does not permit to find robust evidence of the influence of the month of birth, in particular on the first birth decisions. Actually, in order to obtain robust results for the youngest cohort and for the entire sample, we should wait until the end of the period in which they are at risk of getting married and of experiencing a first birth.

Another important element is the potential influence of the already mentioned "primina phenomenon" on the results: in Italy, between 1995 and 2000, on a total of about 2.8 millions of students with a high school diploma, 
8.6 percent qualified before reaching 18 years old or exactly at 18 . Considering the fact that only students that are born after July are still 18 at the timing of graduation from secondary schooling, I can argue that about 3.5\% among them have been enrolled in compulsory schooling before reaching the legal age, precisely before 6 years old. Knowing the importance of sequencing in the Italian structure, the "primina phenomenon" may prevent from catching the long-lasting effects of the month of birth on the adulthood life decisions and it may hinder the natural experiment.

\section{Conclusion}

To overcome this problem, it could be interesting to introduce in the analysis a variable recording this information, especially in order to control it if this element disturbs the level of significance of the coefficients in the regressions. Unfortunately, the I.D.E.A. survey did not provide any information about the age they had when enrolled from compulsory schooling, so it was not possible to include this control in this investigation.

\section{References}

[1] De Sanctis, G. and LiviBacci, M. (2000) Reflections on the economics of the fertility decline in Europe. Paper Presented at Euresco Conference of the 2nd Demographic Transition, Bad Herrenalb.

[2] Van De Kaa and Dirk, J. (2002) The idea of a second demographic transition in industrialized countries. Paper Presented at the 6th Welfare Policy Seminar of the National Institute of Population and Social Security, Tokyo.

[3] Kohler, H.P., Billari, F.C. and Ortega, J.A. (2002 The emergence of lowest-low fertility in Europe during the 1990s. Population and Development Review, 28, 641-680. http://dx.doi.org/10.1111/j.1728-4457.2002.00641.x

[4] Jansen, M. andKalmijn, M. (2002) Investments in family life: The impact of value orientations on patterns of consumption. Production and reproduction in married and cohabiting couples. In: Lesthaeghe, R., Ed. Meaning and Choice: Value Orientations and Life Course Decisions, NIDI/CBGS Publications, The Hague, 129-159.

[5] Barro, R.J. and Becker, G.S. (1988) Fertility choice in a model of economic growth. University of Chicago, Chicago.

[6] Livi Bacci, M. (1997) Abbondanza e scarsità. Le popolazioni d'Italia e d'Europa al passaggio del millennio, IlMulino.

[7] Wolpin, K.I. (1984) A dynamic stochastic model of fertility and child mortality. Journal of Political Economy, 92, 852-874. http://dx.doi.org/10.1086/261262

[8] Hotz, V.J. and Miller, R.A. (1988) An empirical analysis of life cycle fertility and female labor supply. Econometrica, 56, 91-118. http://dx.doi.org/10.2307/1911843

[9] Blossfeld, H.P. and Huinink, J. (1991) Human capital investments or norms of role transition? How women's schooling and career affect the process of family formation. The American Journal of Sociology, 97, 143-168. http://dx.doi.org/10.1086/229743

[10] Becker, G.S. (1991) A treatise on the family. Harvard University Press, Cambridge.

[11] Schultz, T.P. (1993) Investments in the schooling and health of women and men: Quantities and returns, Paper 702, Economic Growth Center, Yale.

[12] Oppenheimer, V.K. (1988) A theory of marriage timing American Journal of Sociology, 94, 563-591. http://dx.doi.org/10.1086/229030

[13] Blossfeld, H.P. and De Rose, A. (1992) Educational expansion and the changes in entry into marriage and motherhood. The experience of italian women. Genus, 48, 73-89.

[14] Corijn, M. (1996) Transition into adulthood in Flanders. Results from the FFS. NIDI/CBGS Publications, The Hague.

[15] Marini, M. (1984) The order of events in the transition to adulthood. Sociology of Education, 57, 63-84. http://dx.doi.org/10.2307/2112630

[16] Blossfeld, H.P. and Jaenichen, U. (1992) Educational expansion and changes in women's entry into marriage and motherhood in the Federal Republic of Germany. Journal of the Marriage and the Family, 54, 302-315. http://dx.doi.org/10.2307/353062

[17] Nicoletti, C. and Tanturri, L. (2005) Differences in delaying motherhood across European countries: Empirical evidence from the ECHP. Working Paper, Institute of Social and Economic Research.

[18] Rosenzweig, M.R. andWolpin, K. (2000) Natural "Natural Experiments" in economics. Journal of Economic Literature, XXXVIII, 827-874. http://dx.doi.org/10.1257/jel.38.4.827

[19] Sander, W. (1992) The effects of ethnicity and religion on educational attainment. Economics of Education Review, 11, 
119-135. http://dx.doi.org/10.1016/0272-7757(92)90003-L

[20] Boulier, B. and Rosenzweig, M.R. (1984) Schooling, search, and spouse selection: Testing economic theories of marriage and household behavior. Journal of Political Economy, 92, 712-32. http://dx.doi.org/10.1086/261253

[21] Lillard, L.A. and Waite, L.J. (1994) A joint model of marital childbearing and marital disruption. Paper 94-16, RAND, Reprint Series.

[22] Fort, M. (2005) Education and the timing of births: Evidence from a natural experiment in Italy. Working Paper, European Centre for Analysis in the Social Sciences, ISER.

[23] Nonaka, K.I. and Nakamura, M., Shimura and Miura, T. (1987) Secondary Sex Ratio and the Month of a Mother's Birth-A Hypothesis of Sex-Ratio-Decreasing Factors. Progress in Biometeorology5, 51-60.

[24] Doblhammer, G. and Vaupel, J.W. (2001) Life span depends on month of birth. Proceedings of the National Academy of Sciences, 98, 2934-2939. http://dx.doi.org/10.1073/pnas.041431898

[25] Angrist, J. and Krueger, A.B. (1991) Does compulsory school attendance affect schooling and earnings? Quarterly Journal of Economics, 106, 979-1014. http://dx.doi.org/10.2307/2937954

[26] Bound, J. and Jaeger, D.A. (1996) On the validity of season of birth as an instrument in wage equations: A comment on Angrist and Krueger's ‘Does compulsory school attendance affect schooling and earnings?’,’ Working Paper No 5835, National Bureau of Economic Research, Cambridge.

[27] Skirbekk, V., Kohler, H.P. and Prskawetz, A. (2003) Completing education and the timing of births and marriage: Findings from a birth-month experiment in Sweden. Working Paper WP-2003-017, Max Planck Institute for Demographic Research, Rostock.

[28] Thompson, A.H., Barnsley, R. and Stebelsky, G. (1991) Born to play ball: The relative age effect and major league basketball. Sociology of Sport Journal, 8, 146-151.

[29] Alton, A. and Massey, A. (1998) Date of birth and achievement in GCSE and GCE A-level. Educational Research, 40, 105-109. http://dx.doi.org/10.1080/0013188980400111

[30] Plug, E.J.S. (2001) Season of birth, schooling and earnings. Journal of Genetic Psychology, 22, 641-660.

[31] Breznitz, Z. and Telesch, T. (1989) The effect of school entrance age on academic achievement and social-emotional adjustment of children: Follow-up study of fourth graders. Psychology in the Schools, 26, 62-68. http://dx.doi.org/10.1002/1520-6807(198901)26:1<62::AID-PITS2310260109>3.0.CO;2-1

[32] Sharp, C. (1995) What's age got to do with it? A study of patterns of school entry and the impact of season of birth on school attainment. Educational Research, 37, 251-265. http://dx.doi.org/10.1080/0013188950370304

[33] Grendler, P. (1989) Schooling in the Renaissance Italy. Literacy and learning, 1300-1600. The Johns Hopkins University Press, London.

[34] Skirbekk, V. (2005) Why not start younger? Implications of the timing and the duration of schooling for fertility, human capital, productivity and public pensions. International Standard Book, IIASA, Vienna. 


\section{Appendices}

\section{Appendix 1.}

Different school levels, International Standard Classification of Education, 1997.

Pre-primary Education, ISCED Level 0. Institution-based and designed for children who are at least 3 years old.

Primary Education, ISCED Level 1. Have systematic introductory studies in core subjects, such as mathematics, reading, and writing. School participation at this level is mandatory in all countries and generally lasts 5-6 years. Entry age varies between 4 years and 8 years.

Lower-Secondary Education, ISCED Level 2. Tends to have somewhat more subject-oriented education, the teachers are more specialized, and the numbers of instruction hours is higher than in primary education. Lowersecondary education is typically the last part of compulsory education.

Upper-Secondary Education, ISCED Level 3. Generally begins at the end of compulsory schooling. In the upper-secondary school, subject teaching is generally more advanced than at earlier stages. Students have considerable freedom to choose specialized subjects. The stage lasts from 1 - 5 years, depending on country and school system.

Postsecondary nontertiary education, ISCED Level 4. Programs sometimes require a secondary school quailfication. They typically have more subject depth, are more specialized than secondary education, and are more often of too short a duration to fit into the ISCED 5 category.

Tertiary education, ISCED Level 5. Programs are more advanced than education offered at ISCED levels 3 or 4 and have a minimum duration of 2 years. They may require completion of a research project or a thesis and are meant to direct the participants to professions with high skill requirements or to research programs.

Advanced tertiary education, ISCED Level 6. Requires the submission of a thesis or dissertation. Students who complete this stage of education should have proved their ability to carry out and advanced research work.

Appendix 2.

\begin{tabular}{|c|c|c|c|c|}
\hline \multicolumn{5}{|c|}{ Descriptive statistics. } \\
\hline Sample size: & 3082 & & & \\
\hline Males:Females: & 1524:1558 & & & \\
\hline Month of birth & Number of observations & $\begin{array}{l}\text { Mean number of years } \\
\text { of Education }\end{array}$ & $\begin{array}{l}\text { Percentage of } \\
\text { married women }^{12}\end{array}$ & $\begin{array}{l}\text { Percentage of women } \\
\text { with a child }{ }^{13}\end{array}$ \\
\hline January & 346 & 13.40 & 27.4 & 24.9 \\
\hline February & 244 & 13.56 & 24.1 & 23.3 \\
\hline March & 248 & 13.66 & 29.8 & 24.6 \\
\hline April & 275 & 13.63 & 26.9 & 25.1 \\
\hline May & 246 & 14.07 & 24.3 & 22.0 \\
\hline June & 238 & 13.82 & 22.6 & 22.2 \\
\hline July & 271 & 13.42 & 24.0 & 21.4 \\
\hline August & 260 & 13.39 & 30.7 & 27.3 \\
\hline September & 223 & 13.16 & 24.7 & 21.1 \\
\hline October & 241 & 13.80 & 23.7 & 22.0 \\
\hline November & 231 & 13.42 & 20.8 & 22.5 \\
\hline \multirow[t]{2}{*}{ December } & 259 & 13.48 & 23.5 & 21.6 \\
\hline & \multicolumn{4}{|c|}{$\underline{\text { Birth cohorts }}$} \\
\hline \multicolumn{2}{|c|}{ Highest completed educational level (percentage): } & 1966-1971 & 1976-1981 & $\begin{array}{l}\text { Number of years of } \\
\text { schooling }\end{array}$ \\
\hline & Compulsory Schooling & $99.5 \%$ & $99.6 \%$ & 8.0 \\
\hline & Lower Secondary School & $80.3 \%$ & $89.7 \%$ & 11.0 \\
\hline
\end{tabular}




\section{Continued}

$\begin{array}{cccc}\text { Upper Secondary Education } & 71.2 \% & 83.9 \% & 13.0 \\ \text { Tertiary Education } & 25.8 \% & 34.9 \% & 16.0 \\ \text { Advanced Education } & 20.5 \% & 13.2 \% & >18.0 \\ & \underline{\text { Males }} & \underline{\text { Females }} & \end{array}$

Highest completed educational level (percentage):

\begin{tabular}{ccc} 
CompulsorySchool & $99.4 \%$ & $99.5 \%$ \\
LowerSecondary School & $83.7 \%$ & $86.3 \%$ \\
Upper Secondary Education & $76.2 \%$ & $78.8 \%$ \\
Tertiary Education & $27.8 \%$ & $33.0 \%$ \\
Advanced Education & $15.6 \%$ & $18.0 \%$ \\
Females: & $\underline{\text { Birth cohorts }}$ \\
\hline & $1966-1971$ & $1976-1981$ \\
& 766 & 792
\end{tabular}

Highest completed educational level (percentage):

$\begin{array}{ccc}\text { CompulsorySchool } & 99.4 \% & 99.5 \% \\ \text { LowerSecondary School } & 81.8 \% & 90.5 \% \\ \text { Upper Secondary Education } & 71.6 \% & 85.7 \% \\ \text { Tertiary Education } & 28.3 \% & 37.5 \% \\ \text { Advanced Education } & 22.4 \% & 14.0 \% \\ \text { who had a first marriage }^{14} & 79.0 \% & 24.0 \% \\ \text { whad a first child } & 71.5 \% & 21.0 \%\end{array}$

\footnotetext{
${ }^{12}$ On a total of 1532 women, 782 are married. 26 missing values are recorded.

${ }^{13} \mathrm{On}$ a total of 1558 women, 717 have at least one child. No missing values are recorded.

${ }^{14}$ Percentage calculated with respect to the sample of women who have provided a positive or negative answer to the question about the experience of first marriage.
} 